\title{
EUROPE SIM (EUROPEAN READINESS FOR PEDIATRIC EXCELLENCE USING SIMULATION) LATVIA
}

\author{
R. Balmaks ${ }^{1,2}$, B. Ziemele ${ }^{1,2}$, M. Blumberga ${ }^{1,3}$, R. Upenieks ${ }^{2}$, T. Whitfill ${ }^{4}$, J. Pavare ${ }^{1,2}$, M. $^{2}$ \\ Auerbach$^{4}$, I. Gross ${ }^{4}$
}

${ }^{1}$ Children's Clinical University Hospital, Riga, Latvia, ${ }^{2}$ Riga Stradins University, Latvia, ${ }^{3}$ The Red Cross Medical College of Riga Stradinš University, Latvia, ${ }^{4}$ Department of Pediatrics, Section of Pediatric Emergency Medicine, Yale School of Medicine, New Haven, Connecticut, US.

Contacts: reinis.balmaks@rsu.Iv

Objective: The purpose of this study was to assess the quality of pediatric acute care in Latvia using metrics assessing the structure and process of care and correlating these metrics with clinical outcomes.

Design: A cross-sectional study.

Setting and Participants: This study was conducted in all Latvian Emergency Departments. The Pediatric Intensive Care Audit Network (PICANet) registry included pediatric patients that were transferred into the national children's Pediatric Intensive Care Unit (PICU) during the study period.

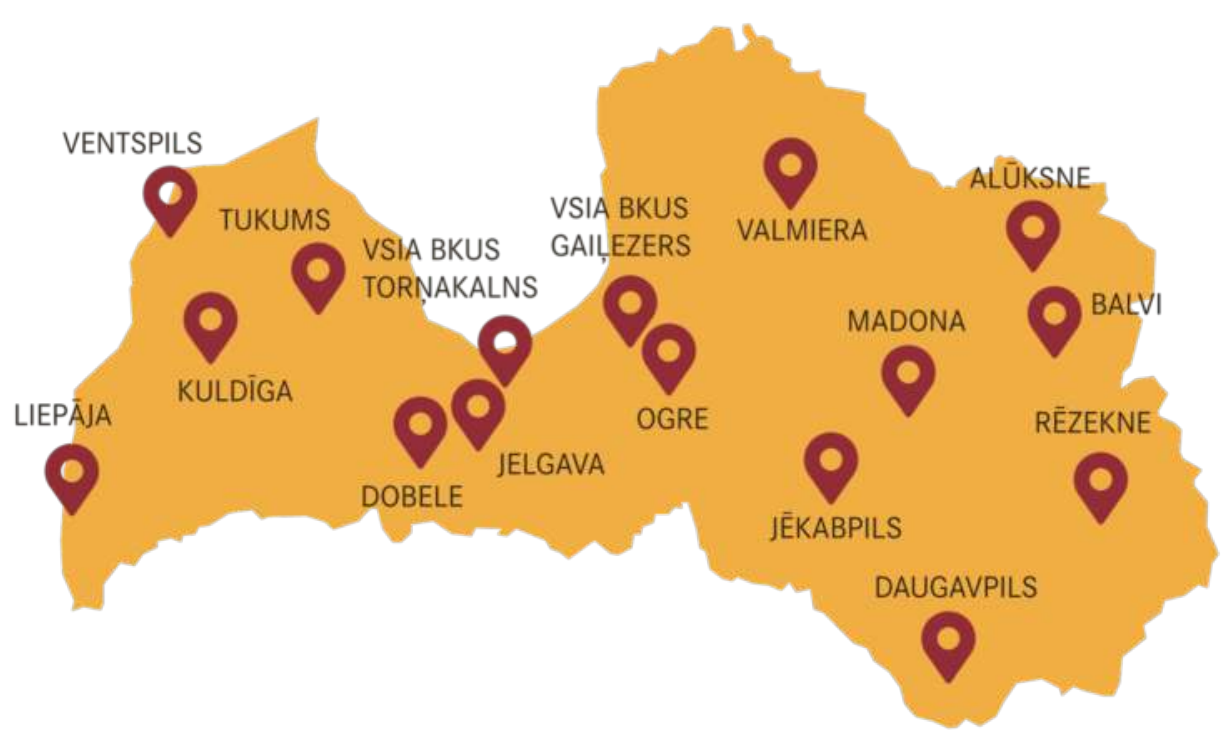

Figure 1. Participating centers

Main Outcomes and Measures: The structure of care was quantified by the Pediatric Readiness Survey (PRS) score. The processes of care were measured using in situ simulations to generate a composite quality score. Clinical outcome data were collected from the PICANet registry. Correlations were explored between composite quality score with Pediatric Readiness Survey score and registry outcome data. Measures were compared between the only pediatric (PED) and 15 general (GED) emergency departments.

Results: 16/16 Latvian hospitals participated with a mean composite quality score of $35.3 / 100$ (SEM=2.6) and a median Pediatric Readiness Survey score of $31 / 100$ (interquartile range: $20,37)$. A total of 254 pediatric patients were emergently admitted and tracked in the patient registry, of which seven $(2.8 \%)$ died during the study period. Higher PRS scores significantly predicted lower length of stay in both the PICU and hospital. There was no correlation between composite quality score and length of stay.

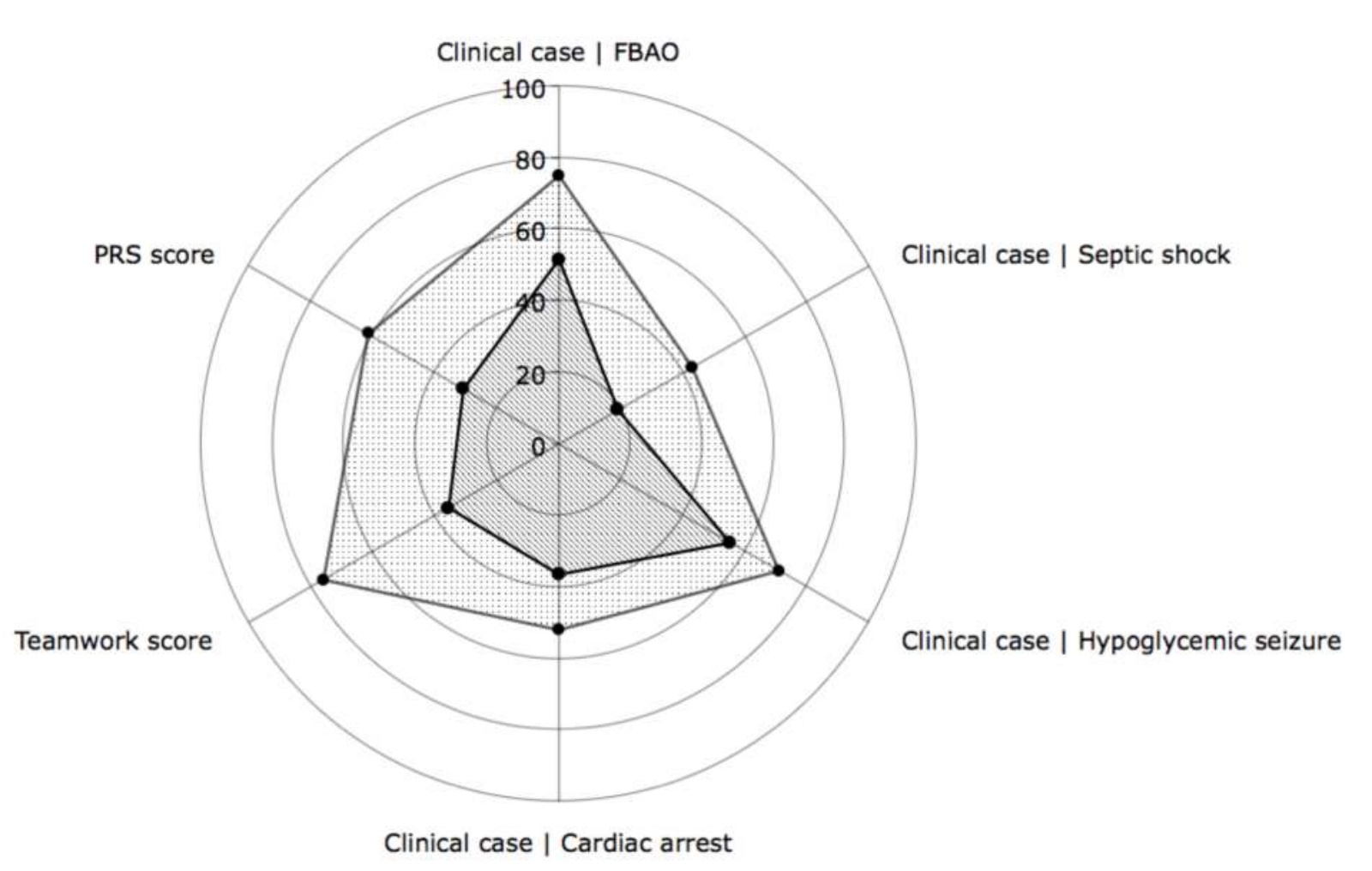

Figure 2. Composite quality score components and PRS score of PED (dotted) and GEDs (striped)

Table 1. Hospital and patient characteristics

\begin{tabular}{|c|c|c|}
\hline & PED & GEDs \\
\hline \multicolumn{3}{|l|}{ Hospital Characteristics } \\
\hline $\begin{array}{l}\text { Total patient volume per year, } \\
\text { median (range) }\end{array}$ & 70000 & $\begin{array}{c}12414 \\
(6254,45638)\end{array}$ \\
\hline $\begin{array}{l}\text { Pediatric patient volume per year, } \\
\text { median (range) }\end{array}$ & 70000 & $\begin{array}{c}2707 \\
(809,7160)\end{array}$ \\
\hline \multicolumn{3}{|c|}{ Patient Characteristics (transferred to PICU) } \\
\hline $\mathrm{N}$ & 172 & 82 \\
\hline LOS ICU, & $2.4(0.03)$ & $2.3(0.3)$ \\
\hline LOS Hospital, mean days (SEM) & $15.1(2.3)$ & $15.3(1.6)$ \\
\hline PICU mortality (\%) & $6(3.5)$ & $0(0)$ \\
\hline 30-day mortality (\%) & $6(3.5)$ & $1(1)$ \\
\hline
\end{tabular}

Table 2. Correlations between measures of structure and process of care and patient outcomes

\begin{tabular}{|c|c|c|c|c|}
\hline & \multicolumn{2}{|c|}{ LOS PICU } & \multicolumn{2}{|c|}{ LOS Hospital } \\
\hline & $\begin{array}{c}\text { Adjusted }{ }^{*} \beta \\
(95 \% \mathrm{Cl})\end{array}$ & $p$ & $\begin{array}{c}\text { Adjusted* } \beta \\
(95 \% \mathrm{Cl})\end{array}$ & $p$ \\
\hline $\begin{array}{l}\text { Pediatric } \\
\text { readiness score }\end{array}$ & $\begin{array}{c}-0.06 \\
(-0.1,-0.01)\end{array}$ & 0.021 & $\begin{array}{c}-0.36 \\
(-0.61,-0.1)\end{array}$ & 0.011 \\
\hline $\begin{array}{l}\text { Composite } \\
\text { quality score }\end{array}$ & $\begin{array}{c}0.01 \\
(-0.06,0.07) \\
\end{array}$ & 0.839 & $\begin{array}{c}0.05 \\
(-0.20,0.3)\end{array}$ & 0.661 \\
\hline
\end{tabular}

score, composite quality score, and annual pediatric patient volume

Conclusion and Relevance: These data provide a national assessment of pediatric acute care and metrics for repeated measurement of structure, process and outcomes crosssectionally in Latvia. The quality of structure of care measured by PRS score correlated with patient outcomes. Expectedly, the only PED outperformed GEDs. 